\title{
Research Methods for Plant Health Detection using Computer Vision Techniques: A Survey
}

\author{
Nagamani H S \\ (Research Scholar) \\ Assistant Professor, Dept. of Computer Science \\ Smt. V H D central Institute of Home Science \\ Seshadrei Road, Bangalore, India.
}

\author{
Dr. Saroja Devi. H \\ Professor \\ Dept. Computer Science and Engineering \\ NITTE Research and Education Academy \\ NMIT, Bangalore-64, India.
}

\begin{abstract}
The agricultural production is that thing on which Indian Economy greatly depends. This is one of the reasons that disease detection in plants plays a significant role in the agriculture field, as contain the disease in plants is quite natural. If proper care is not taken in this region then it causes serious effects on plants and because of which respective product quality, quantity or productivity is affected. Plants have become an important source of energy, and are a fundamental piece in the puzzle to solve the problem of global warming. It is very difficult to monitor the plant diseases manually. It requires a tremendous amount of work, expertise in plant diseases, and also requires excessive processing time. Hence, image processing is used for the detection of plant diseases. Plant disease detection through some automatic technique is beneficial as it reduces a large work of monitoring in big farms of crops and at a very early stage itself it detects the symptoms of diseases means when they appear on plant leaves. In this proposed paper literature survey is done to study the different types of image processing technique, which helps to detect the plant disease using image processing.
\end{abstract}

Keywords: Captured plant images, Image segmentation, Feature extraction and Classifier.

\section{INTRODUCTION}

India is one of the developing countries wherein the majority of the population of the country depends on agriculture and agricultural production [12]. A recent survey proves that the plant leaf disease condenses the quality and quantity of agricultural products. Therefore identification and detection of disease at an early stage is an important task for farmers. Detection of disease at the beginning stage can save the entire crops from disease. The recognition and identification of plant leaf disease by the open naked eye is quite a difficult task for farmers and consult scientist or expertise person is very costly for farmers in our developing countries like India.

In India, agriculture is the backbone of the economy. More than half of the population in the world has been involved in farming activities directly or indirectly [2]. Many varieties of cereals, fruits and vegetables are produced in one country and will be exported to other countries. Hence it is essential to fabricate high-quality products with an optimal yield. As diseases of the plants are inevitable, plant disease identification is necessary for the field of Agriculture. In plants, diseases can be found in different parts such as stems, fruits, and leaves. The

Major diseases of plants are a fungus, a viral and bacterial disease like Alternaria, Anthracnose, bacterial spot, canker, etc. The viral disease is generally due to environmental changes, fungus disease is due to the presence of fungus in the leaf and bacterial disease is due to the presence of germs in leaf or plants [1]. Automatic detection of plant diseases is an important research topic since it is able to automatically detect the diseases from the symptoms that appear on the plant leaves.

In agriculture appliances, diseases and pests cause higher economic loss to farmers through condensed yields and increased costs of pesticides and other control measures. Plant disease detection by the visual way is a difficult task and it is less accurate hence automation techniques are developed to ease the task and provide high accuracy [3]. With the help of image processing techniques, it is feasible to enhance the cultivation yield by building a decision support system that can identify and classify the disease.

To identify the affected area, the images of different leaves are collected with a digital camera or similar device. Figure 1 shows an overview of detecting leaf disease. Then to process those images, different image-processing techniques are applied to them to get different and helpful features required for later analyzing purpose. Image segmentation is one of the most important parts of image analysis which separates the relevant information from the input image. Further different feature extraction methods are used to enhance the quality of the segmented image, the diseased part of the plant is predicted by using different classifier techniques.

The rest of the paper is formed as follow: Section II explains the different techniques that have been studied as a part of the literature survey. Section III explains comparative analysis of different approaches. Lastly, we conclude the survey paper in Section IV followed by the reference.

\section{LITERATURE SURVEY}

This section describes the literature survey of the disease analysis of the plant disease using image processing methods. The affected part of the plant region is scanned and analyzed by using image segmentation methods. There is various segmentation methods are available separate the abnormal part in the plant image. Further, several feature extraction techniques are considered to separate the particular features of 


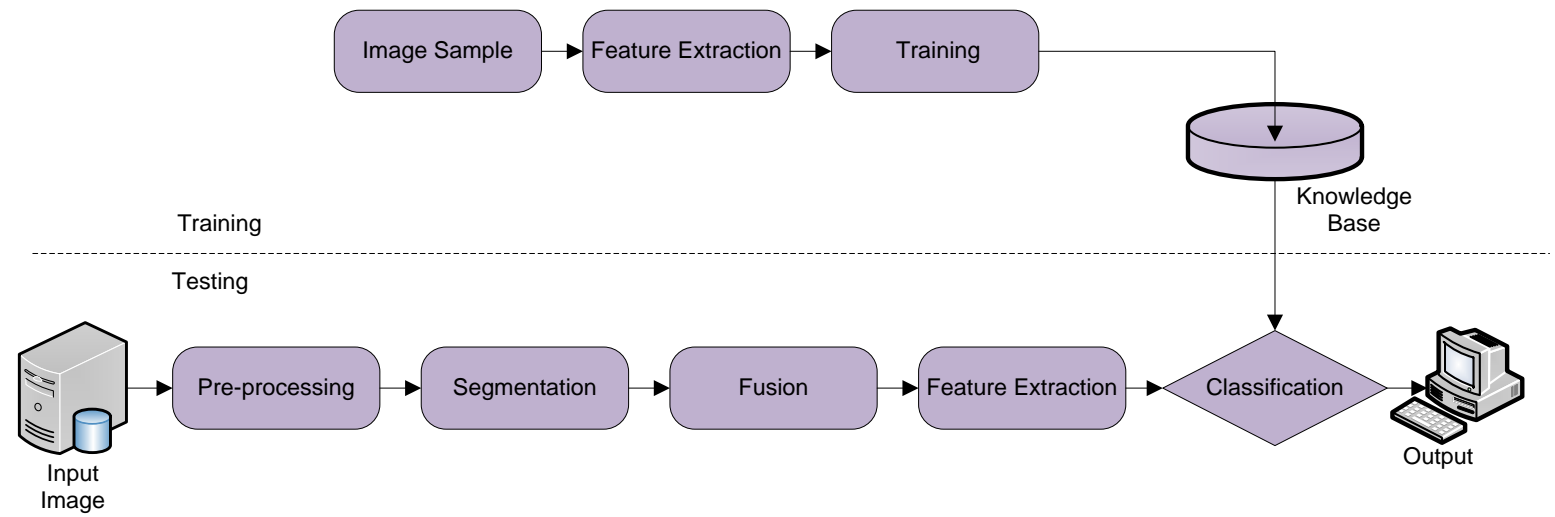

Figure 1: Overview of Plant Disease Detection Model

the segmented image. Feature extraction is a process which recognizes the similar patterns in the segmented image and transferred to the next classifier section in disease prediction. Different users explain different classifier in stage prediction of the plant disease using machine learning algorithm. The main purpose of the literature survey has explained the advantages and application of various image processing techniques during stage prediction of the plant disease.

\subsection{Segmentation:}

Image segmentation is a basic computer analysis technique used in image processing. The word the image segmentation is defined as the process of representing the digital image into a number of various segments based on a set of the pixel value. Image segmentation plays an important role in image analysis, which helps the examiner to identify the different part presented in the given image.

Smita Naikwadi et.al [1] has presents advanced image segmentation techniques used for leaf disease detection. Early leaf disease detection is essential to maintain the natural chain. The referred paper describes system models which process the given image and segment the diseased part which can be helpful for the classifier to make to a final decision. For segmentation, a color-based segmentation (i.e. green plane) algorithm and ostu's algorithm is considered to meet the better accuracy level. In experimental result system designer concluded that designed module presents an acceptable output.

Sachin D. Khirade et.al [12] discussed different techniques for segmenting the diseased part of the plant. The segmentation techniques which are boundary and spot detection, K-mean clustering and Otsu thresholding are used. Some feature extraction and classification methods are used to extract features of infected leaf and plant disease classification. The ANN technique is used for classification of disease in plants such as self-organizing feature map. Backpropagation algorithm, SVM etc may be efficiently used. From these techniques, they can properly identify and classify different plant disease utilizing image processing techniques.

\subsection{Feature extraction}

Feature extraction is the most basic machine learning algorithm used in image processing. It is mainly used to reduce the dimension of the input image when the given image information is very large which leads increase in the computation complexity during image analysis. Their different types of feature selection and extraction algorithm are available for better image enhancement. Survey of the various feature extraction associated with plant disease analysis is explained below.

Sanjay B. Dhaygude et.al [2], the plant leaf disease detection is a very important task to avoid a serious outbreak. Automatic recognition of plant disease is necessary to research topic. Most plant diseases are caused by bacteria, fungi, and viruses. Fungi are recognized primarily from their morphology, with emphasis placed on their reproductive structures. Bacteria are considered more primitive than fungi and generally have simpler life cycles. The term disease is usually used only for the destruction of live plants. The developed processing scheme consists of four main steps, first, a color transformation structure for the input RGB image is created, this RGB is converted to HSI because RGB is for color generation and his for color descriptor. Then green pixels are masked and removed using specific threshold value, then the image is segmented and the useful segments are extracted, finally, the texture statistics are computed. Finally, the presence of diseases on the plant leaf is evaluated.

Song Kai et.al [3], proposed maize disease image recognition of corn leaf based on image processing and image disease classification. According to the texture characteristics of corn diseases, it uses $\mathrm{YCbCr}$ color space technology to segment disease spot, and uses the co-occurrence matrix spatial gray level layer to extract disease spot texture feature, and uses BP neural network to class the maize disease. Application $\mathrm{YCbCr}$ color space technology segmented disease spot and using the co-occurrence matrix spatial gray level layer extracted disease spot texture feature of using BP neural network, on maize disease classification identification. On $\mathrm{VC}++$ platform, do experiments for the study design recognition algorithm ,the experimental results show that the algorithm can effectively identify the disease image, the accuracy was as high as $98 \%$ or more, the study provided the theoretical basis to cognition of 
maize leaf disease the image re of maize leaf disease image recognition to provide a theoretical basis.

Dheeb Al Bashish et.al [4] has proposed and evaluates a work to find plant leaf/ stem disease. The proposed system gives fast, automatic, cost reduced and more accurate image processing based solution for detection of plant disease with real significance. The system carries with the following steps, in the first steps the image is segmented in hand using the $\mathrm{K}$ means algorithm, once the segmentation is done, and the preprocessed image went through the neural network. As a testbed, a group of leaf images is considered from Al-Ghor area in Jordan. The proposed system results show that the increased accuracy and automatic segmentation of detected disease. The neural network is used as a classifier to classify out the leaf disease. .

\section{3 . Classifier}

Classifiers are gaining more importance in disease prediction. Classifiers are one of the application methods of plant disease detection which recognizes the significant part from the collected image. The application of plant disease detection classifier techniques reduces the computational complexity associated with disease prediction in plants. The survey is conducted for various classifier used in disease prediction of the plants.

Sujeet Varshney et.al [5] has presented a brief review of classification accuracy machine learning classifiers in leaf disease detection. Advanced image processing includes a set of classification algorithms but each system response is different for the different dataset. The referred paper briefly studied the individual classifier response for separate leaf dataset and presents its classifier accuracy but in the end, it is concluded that classifier accuracy may be changed as the data set is changed.

Bed Prakash et.al [6] has presents a survey paper on plant diseases techniques using different computer vision algorithms. Initially, the referred paper studied types of the disease occurred in different plants and further model is tested with different dataset. In a referred paper system performance is tested with a neural network, genetic algorithm, PCA. Testing with multiple samples it is concluded that PNN presents faster response in classification.

Zhang Jian et.al [7] presents a cucumber leaf disease detection model using support vector classifier. The designed module includes multiprocessing steps. Initially, the given image is processed with pre-processing techniques, the further processed output is passed to feature extraction blocks. A color based and texture based features are collected to train the classifier. SVM classifier is used for disease classification. The application of the RBF kernel improves the recognition rate.

Jayme Garcia Arnal. Barbedo et.al [8], this discussion based on digital image processing techniques to discover, classify and quantify plant diseases from digital images in the visible spectrum. Although symptoms of the disease can manifest in any portion of the plant, only techniques that investigate visible symptoms in leaves and stems were considered. Based on their objective the selected proposals are divided into three classes namely: detection, severity quantification, and classification. Each of such classes, in turn, is sub-divided according to the major technical solution employed in the technique. This study is expected to be helpful to researchers investigating both vegetable pathology and pattern recognition, providing a complete and accessible summary of this important area of research.

D. S. Guru et.al [9], proposed a machine vision based strategy for classification of tobacco leaves for automatic harvesting in a complex agricultural environment. The CIELAB color space scheme is applied to segment the leaf from the background. After completion of the segmentation process, classification takes place which is classified into three classes namely, ripe, unripe, and over-ripe. Models based on various textural features such as GLTP (Gray Level Local Texture Patterns), LBP (Local Binary Pattern) and LBPV (Local Binary Pattern Variance) are studied in this research work. The K-Nearest Neighbor (K-NN) classifier based on the Euclidean distance measure has been applied for classification. In this experiment dataset consisting of 244 images of tobacco leaves and images are captured in both sunny and cloudy lighting conditions in a real field of tobacco.

Anand H. Kulkarni et.al [10], proposed a methodology for detecting plant diseases early and correctly, applying diverse image processing methods and artificial neural network (ANN). Farmers are facing great difficulties in changing from one virus control policy to another. The proposed work main intention is to develop a simpler disease recognition scheme for plant diseases. The work begins with capturing the pictures. Gabor filter is applied to filter an image also segment an image. Then, the classification process is done by using Artificial Neural Network (ANN).

Vijai Singh et.al [11] introduced an algorithm for image segmentation process which is utilized for automatic detection and classification of plant leaf diseases. It as well completes survey on dissimilar disease classification methods that may be utilized for plant leaf disease detection. The image segmentation is done by using the genetic algorithm, which is a significant aspect for the detection of the disease in plant leaf disease detection.

Sachin D. Khirade et.al [12] discussed different techniques for segmenting the diseased part of the plant. The segmentation techniques which are boundary and spot detection, K-mean clustering and Otsu thresholding are used. Some feature extraction and classification methods are used to extract features of infected leaf and plant disease classification. The ANN technique is used for classification of disease in plants such as self-organizing feature map. Backpropagation algorithm, SVM etc may be efficiently used. From these techniques, they can properly identify and classify different plant disease utilizing image processing techniques.

Rajneet Kaur et.al [13] this paper is about automatic detection of disease and pathological part present inside the leaf image of plants and even inside the agriculture crop production it is 
through with advancement of technology that assists in farming to enlarge production. Initially, there is the downside of detection accuracy and in neural network approach SVM (Support Vector Machine) is exist already. During this analysis, an entirely unique approach can design to expand accuracy victimization KNN. During this analysis work, they are going to work upon the advancement of plant diseases prediction techniques and going to propose an entirely unique approach for the detection rule.

Vijai Singh et.al [14] surveyed on different disease classification methods that may be utilized for plant leaf disease detection and an algorithm for image segmentation method utilized for automatic detection as well classification of plant leaf disease has been explained later. The proposed algorithm was tested on some species which are Mango, tomato, sapota, banana, jackfruit, beans, potato, and lemon. Therefore, related diseases for these plants were taken for identification. The optimum results were obtained with very less computational efforts, which as well show the efficiency of the proposed algorithm in recognition and classification of leaf diseases. One more advantage of utilizing this technique is that the plant disease may be identified at an early stage or initial stage. To enhance the recognition rate in classification process ANN (Artificial Neural Network), Fuzzy Logic, Bayes classifier, and the hybrid algorithm can as well be utilized

Sharada P Mohanthy [15], the researchers have conducted research to detect agricultural plant leaf diseases using image processing and deep learning techniques on smartphones. They conducted their research on 54,306 plant leaves to identify 14 crop species with 26 diseases. The dataset taken to conduct the research had assigned into 38 crop-disease pair class labels and deep convolutional neural networks model was used to classify the diseases into the class labels. Although different performance measures were used to investigate the ability to predict, the best performing model achieved a mean F1 score of $99.35 \%$. To evaluate the applicability of deep convolutional neural network approach, the researchers focused on AlexNet and GoogleNet architectures. As AlexNet has 5 conventional, 3 fully connected and softmax layers, GoogleNet architecture has 22 layers. The researchers have used these conventional neural network architectures in different configurations by training the model from scratch in one case, and then by adapting already trained models using transfer learning. Finally, GoogleNet is found to be better performing than AlexNet architecture. In the case of the dataset used (color, grayscale and segmented), the models performed best in the case of the colored version of the dataset.

\section{COMPARATIVE ANALYSIS OF DIFFERENT APPROACHES}

The comparative analysis of different approaches is depicted in Table 1, Table 2 and Table 3 respectively. The survey tables shows the segmentation, feature extraction and classification techniques used for detecting the unhealthy region in leaf.
Table 1: Survey on Segmentation Algorithms

\begin{tabular}{|c|c|c|c|c|}
\hline Title & Year & Algorithm & Advantage & Improvement \\
\hline $\begin{array}{c}\text { Advances } \\
\text { In Image } \\
\text { Processing } \\
\text { For } \\
\text { Detection } \\
\text { Of Plant } \\
\text { Diseases[1] }\end{array}$ & 2013 & $\begin{array}{l}\text { Color Based } \\
\text { Segmentation } \\
\text { and Ostu's } \\
\text { Segmentation } \\
\text { Algorithm }\end{array}$ & $\begin{array}{l}\text { Detecting the } \\
\text { Diseases in } \\
\text { planes } \\
\text { presents a } \\
\text { better } \\
\text { precision } \\
\text { level }\end{array}$ & $\begin{array}{c}\text { Achieved } \\
\text { precision } \\
\text { between } 83 \% \text { - } \\
94 \%\end{array}$ \\
\hline $\begin{array}{c}\text { Plant } \\
\text { Disease } \\
\text { Detection } \\
\text { Using } \\
\text { Image } \\
\text { Processing } \\
\text { [12] }\end{array}$ & 2015 & $\begin{array}{c}\text { Boundary } \\
\text { and spot } \\
\text { detection, K- } \\
\text { mean } \\
\text { Clustering, } \\
\text { Otsu } \\
\text { Thresholding }\end{array}$ & $\begin{array}{l}\text { The K- } \\
\text { means } \\
\text { clustering is } \\
\text { used for } \\
\text { classification } \\
\text { of the object } \\
\text { based on a } \\
\text { set of } \\
\text { features into } \\
\text { K number of } \\
\text { classes. } \\
\text { Thresholding } \\
\text { creates } \\
\text { binary } \\
\text { images from } \\
\text { grey-level } \\
\text { images }\end{array}$ & $\begin{array}{l}\text { helps to } \\
\text { find the } \\
\text { infected part } \\
\text { of the leaf }\end{array}$ \\
\hline
\end{tabular}

Table 2: Survey on Feature Extraction Algorithms

\begin{tabular}{|c|c|c|c|c|}
\hline Title & Year & Algorithm & Advantage & Improvement \\
\hline $\begin{array}{c}\text { Agricultural } \\
\text { Plant Leaf } \\
\text { Disease } \\
\text { Detection } \\
\text { Using Image } \\
\text { Processing } \\
{[2]}\end{array}$ & 2013 & $\begin{array}{c}\text { Color Co- } \\
\text { occurrence } \\
\text { Matrix, } \\
\text { Texture }\end{array}$ & $\begin{array}{l}\text { The texture } \\
\text { statistics are } \\
\text { computed } \\
\text { and the } \\
\text { presence of } \\
\text { diseases on } \\
\text { the plant leaf } \\
\text { is evaluated }\end{array}$ & $\begin{array}{l}\text { The extension } \\
\text { of this work is } \\
\text { to increase the } \\
\text { recognition rate } \\
\text { of the } \\
\text { classification } \\
\text { process }\end{array}$ \\
\hline $\begin{array}{c}\text { A Research of } \\
\text { Maize Disease } \\
\text { Image } \\
\text { Recognition of } \\
\text { Corn-Based } \\
\text { on BP } \\
\text { Networks } \\
\text { [3] }\end{array}$ & 2011 & $\begin{array}{c}\text { BP neural } \\
\text { network } \\
\text { and } \\
\text { distill } \\
\text { features }\end{array}$ & $\begin{array}{c}\text { The } \\
\text { algorithm } \\
\text { can } \\
\text { effectively } \\
\text { identify the } \\
\text { disease } \\
\text { image }\end{array}$ & $\begin{array}{c}\text { Promising } \\
\text { Result }\end{array}$ \\
\hline $\begin{array}{c}\text { Framework } \\
\text { for Detection } \\
\text { and } \\
\text { Classification } \\
\text { of Plant Leaf } \\
\text { and Stem } \\
\text { Diseases } \\
\text { [4] }\end{array}$ & 2010 & $\begin{array}{l}\text { Color Co- } \\
\text { occurrence } \\
\text { Method } \\
(\mathrm{CCM})\end{array}$ & $\begin{array}{l}\text { Both the } \\
\text { color and } \\
\text { texture of an } \\
\text { image are } \\
\text { taken into } \\
\text { account, to } \\
\text { arrive at } \\
\text { unique } \\
\text { features, } \\
\text { which } \\
\text { represent } \\
\text { that image. }\end{array}$ & $\begin{array}{c}\text { Promising } \\
\text { Result }\end{array}$ \\
\hline
\end{tabular}


Table 3: Survey on Classifier Techniques

\begin{tabular}{|c|c|c|c|}
\hline Title & Year & Algorithm & Performance \\
\hline $\begin{array}{c}\text { Plant Disease } \\
\text { Prediction using } \\
\text { Image } \\
\text { Processing } \\
\text { Techniques- A } \\
\text { Review[5] }\end{array}$ & 2016 & $\begin{array}{l}\text { Bayes, SVM, } \\
\text { Ostu's, PNN } \\
\text { and K-Means }\end{array}$ & $\begin{array}{l}\text { Performance is } \\
\text { changed as } \\
\text { dataset changed }\end{array}$ \\
\hline $\begin{array}{c}\text { Cucumber Disease } \\
\text { Detection Using } \\
\text { Artificial } \\
\text { Neural Network } \\
\text { [7] }\end{array}$ & 2016 & $\begin{array}{c}\text { ANN } \\
\text { (Artificial } \\
\text { Neural } \\
\text { Network) }\end{array}$ & $\begin{array}{l}\text { ANN Achieves } \\
80.45 \% \text { Accuracy }\end{array}$ \\
\hline $\begin{array}{c}\text { Machine Vision } \\
\text { Based Classification } \\
\text { of Tobacco Leaves } \\
\text { for Automatic } \\
\text { Harvesting } \\
\text { [9] }\end{array}$ & 2012 & $\begin{array}{c}\text { K-NN } \\
\text { Classifier }\end{array}$ & $\begin{array}{l}\text { The extension of } \\
\text { this work is to } \\
\text { study the } \\
\text { classification of } \\
\text { tobacco leaves } \\
\text { using a fusion of } \\
\text { different texture } \\
\text { and } \\
\text { color features, }\end{array}$ \\
\hline $\begin{array}{c}\text { Applying Image } \\
\text { Processing } \\
\text { Technique to Detect } \\
\text { Plant Diseases } \\
\text { [10] }\end{array}$ & 2012 & $\begin{array}{l}\text { Artificial } \\
\text { Neural } \\
\text { Network }\end{array}$ & $\begin{array}{c}\text { Achieves } 91 \% \\
\text { Accuracy. }\end{array}$ \\
\hline $\begin{array}{c}\text { Detection of plant } \\
\text { leaf diseases using } \\
\text { the image } \\
\text { segmentation and } \\
\text { soft computing } \\
\text { techniques } \\
{[11]}\end{array}$ & 2017 & SVM & $\begin{array}{l}\text { SVM Achieves } \\
95.71 \% \text { Accuracy }\end{array}$ \\
\hline $\begin{array}{l}\text { A Survey on Plant } \\
\text { Leaf Disease } \\
\text { Identification[12] }\end{array}$ & 2015 & $\begin{array}{c}\text { A neural } \\
\text { network, PCA, } \\
\text { Genetic } \\
\text { Algorithms }\end{array}$ & $\begin{array}{l}\text { PNN Presents } \\
\text { Faster Response }\end{array}$ \\
\hline $\begin{array}{l}\text { Using deep learning } \\
\text { for image } \\
\text { processing[15] }\end{array}$ & 2016 & $\begin{array}{l}\text { Convolutional } \\
\text { neural } \\
\text { network } \\
\text { architectures }\end{array}$ & $\begin{array}{l}\text { CNN Achives } \\
95 \% \text { Accuracy }\end{array}$ \\
\hline
\end{tabular}

\section{CONCLUSION}

In this paper a survey on different segmentation methods is done and briefly explains the advantage and limitation of the individual segmentation algorithm in the detection of plant disease. In combining with that the feature extraction techniques introduced and explained how it helps in the reorganization of plant disease. Different classification techniques have presented and explained the significant role of the individual classifier in detecting or predicting the plant disease. With this plant disease detection technique, the use of harmful chemicals on plants may be reduced and therefore ensure a healthier environment. This explains that there is a lot of work is done in this sector but still, there is a need to make the agriculture sector more effective in detecting the plant disease at its initial stage.

\section{REFERENCE}

[1] Smita Naikwadi and Niket Amoda, "Advances in Image Processing for Detection of Plant Disease", International Journal of Application or Innovation in Engineering and Management, Vol. 2, Issue 11, 2013.

[2] Sanjay B. Dhaygude and Nitin P. Kumbhar, "Agricultural Plant Leaf Disease Detection Using Image Processing", International Journal of Advanced Research in Electrical, Electronics and Instrumentation Engineering, Vol. 2, No. 1, pp. 599-602, 2013. (Fea 001).

[3] Song Kai, Liu Zhikun, Su Hang and Guo Chunhong, "A Research of Maize Disease Image Recognition of CornBased on BP Networks", In Measuring Technology and Mechatronics Automation (ICMTMA), IEEE, Vol. 1, pp. 246-249, 2011. (Featu 002).

[4] Al Bashish, D., Braik, M. and Bani-Ahmad, S., "A Framework for Detection and Classification of Plant Leaf and Stem Diseases", IEEE International Conference, In Signal and Image Processing (ICSIP), pp. 113-118, 2010.

[5] Sujeet Varshney, and Tarun Dalal, "Plant Disease Prediction Using Image Processing Techniques-A Review", International Journal of Computer Science and Mobile Computing, Vol. 5, Issue 5, pp. 394-398, 2016.

[6] Prakash, Bed, and Amit Yerpude, "A Survey on Plant Leaf Disease Identification", International Journal of Advanced Research in Computer Science and Software Engineering (IJARCSSE), Vol. 5, Issue 3, 2015.

[7] Zhang Jian, and Zhang Wei, "Support Vector Machine for Recognition of Cucumber Leaf Diseases." In Advanced Computer Control (ICACC), 2010 2nd International Conference on, Vol. 5, pp. 264-266. IEEE, 2010 .

[8] Jayme Garcia Arnal. Barbedo, "Digital Image Processing Techniques for Detecting, Quantifying and Classifying Plant Diseases", Springer, Vol. 2, No. 1, pp. 660, 2013.

[9] D. S. Guru, P. B. Mallikarjuna, S. Manjunath and M. M. Shenoi, "Machine Vision Based Classification of Tobacco Leaves for Automatic Harvesting", Intelligent Automation \& Soft Computing, Vol. 18, No. 5, pp. 581590, 2012.

[10] Anand H. Kulkarni and Ashwin Patil, "Applying Image Processing Technique to Detect Plant Diseases", International Journal of Modern Engineering Research, Vol. 2, No. 5, pp. 3661-3664, 2012.

[11] Singh, V. and Misra, A.K., "Detection of Plant Leaf Diseases using Image Segmentation and Soft Computing Techniques", Information Processing in Agriculture, Vol. 4, No. 1, pp. 41-49, 2017.

[12] Sachin D Khirade and Patil, A.B., "Plant Disease Detection using Image Processing", IEEE International Conference, In Computing Communication Control and 
International Journal of Applied Engineering Research ISSN 0973-4562 Volume 14, Number 7 (2019) pp. 1627-1632 (C) Research India Publications. https://dx.doi.org/10.37622/IJAER/14.7.2019.1627-1632

Automation (ICCUBEA), pp. 768-771, 2015.

[13] Ranjeet Kaur and Kaur, M.M., "A Brief Review on Plant Disease Detection using in Image Processing", International Journal of Computer Science and Mobile Computing, Vol. 6, No. 2, pp. 101-106, 2017.

[14] Singh, V. and Misra, A.K., "Detection of Unhealthy Region of Plant Leaves using Image Processing and Genetic Algorithm", IEEE International Conference, In Computer Engineering and Applications (ICACEA), pp. 1028-1032, 2015.
[15] Sharada P.Mohanty, DavidP.Hughes and MarcelSalathe, "Using Deep Learning for Image-Based Plant Disease Detection", Frontiers in Plant Science www.frontiersin.org, September 2016 | Volume 7 | Article 1419. 